\title{
COMPOSIÇÃO DE CANTEIROS NA ARBORIZAÇÃO DE RUAS DE CURITIBA (PR)
}

\author{
Rogério Bobrowski ${ }^{1}$, Daniela Biondi ${ }^{2}$, Damaris Baggenstoss ${ }^{3}$
}

(recebido em 08.12.2008 e aceito para publicação em 30.06.2009)

\section{RESUMO}

A utilização dos canteiros nas calçadas das ruas de Curitiba, Estado do Paraná (Brasil), para a formação de uma composição paisagística é uma realidade urbana, porém desmotivada, principalmente pelas dimensões dos canteiros e pela falta de sugestões técnicas. Tradicionalmente, os canteiros são ocupados por grama, mas ocasionalmente ocorre o plantio de outras espécies vegetais para forração do solo. O objetivo desta pesquisa foi fazer um levantamento exploratório sobre a composição florística de calçadas em Curitiba (PR), especificando as características das calçadas (áreas permeáveis), das árvores e da vegetação encontrada nos canteiros da arborização de ruas. Houve variação expressiva na taxa de permeabilidade das calçadas avaliadas, bem como, significativa diversidade de espécies de forração utilizadas pela população local em substituição ao gramado comumente utilizado. Há, porém, necessidade de estudos detalhados sobre as possíveis e melhores formas de composição paisagística, suas relações com as árvores da arborização de ruas, as necessidades de manejo prévio do solo, os benefícios diversos e as influências sobre a qualidade e gestão de águas pluviais.

Palavras-chave: arborização urbana, paisagismo, plantas de forração, composição paisagística.

\footnotetext{
${ }^{1}$ Engenheiro Florestal, Secretaria Municipal de Meio Ambiente (Prefeitura de Curitiba-PR). Mestrando em Engenharia Florestal-UFPR. Rua Anita Garibaldi, 1204, apto 103, bloco B, Juvevê - Curitiba/PR. CEP: 80540-180.E-mail: bobrowski_roger@yahoo.com.br

${ }^{2}$ Engenheira Florestal, Dra., Professora Depto. Ciências Florestais, Universidade Federal do ParanáUFPR, Bolsista Produtividade em Pesquisa - CNPq, Curitiba-PR.. e-mail: dbiondi@ufpr.br

${ }^{3}$ Bacharel em Composição Paisagística. e-mail: damaris_bg@yahoo.com.br
} 


\title{
FLOWERBED COMPOSITION ON STREET ARBORIZATION OF CURITIBA (PR)
}

\begin{abstract}
The utilization of flowerbeds on sidewalks of Curitiba's street, Paraná State (Brazil), to make a landscape composition is an urban reality, however it is desmotivated, mainly by flowerbeds dimensions an by the lack of technical suggestions. Traditionally, the flowerbeds are occupied by grass, but occasionally happen the planting of other vegetables species to cover the soil. The objective of this research was to do an exploratory survey about sidewalks floristic composition in Curitiba, specifying the characteristics of the sidewalks (permeable areas), trees and vegetables found on flowerbeds of street arborization. It had an expressive variation on permeability rate of evaluated sidewalks and significant groundcover species diversity used by local population instead of grass, which is commonly used. There's, however, the necessity of detailed studies about the best and possible ways of landscape composition, their relations with trees of street arborization, the necessities of previous management of soil, the various benefits and the influences over the quality and management of rainwater.
\end{abstract}

Key-words: urban arborization, landscaping, groundcover plants, landscape composition. 


\section{INTRODUÇÃo}

O contato com o ambiente natural, o trato e cultivo de organismos ou componentes da natureza, tais como espécies arbustivas, herbáceas e arbóreas, faz parte da cultura humana e traz diversos benefícios às pessoas. Porém, estas não se beneficiam apenas com o contato direto (jardinagem), mas também através de experiências passivas, como a observação de áreas verdes ou jardins.

Boa parte do tempo diário das pessoas é gasto nas ruas, e algumas dessas ruas não são atrativas aos pedestres e motoristas. Para Jacobs ${ }^{4}$, citado por Todorova et al. (2004), as ruas deveriam ser confortáveis, com espaços para caminhar como lazer, em segurança, e ter alguma coisa para ocupar os olhos.

Dentro desse espaço de lazer urbano que pode ser proporcionado pelas calçadas, está a arborização de ruas como componente da arborização urbana de uma cidade.

Mesmo sendo uma área de estudo incipiente no Brasil, muito se tem escrito sobre as importâncias da arborização urbana e suas funções dentro do ecossistema urbano, porém, na maioria das vezes, atentando-se quase que essencialmente sobre a composição das espécies arbóreas (espécies, número de indivíduos, porte, etc).

Pouca ou quase nenhuma informação é disponibilizada sobre a relação entre arborização das ruas e os canteiros, ou melhor, sobre a influência da composição dos canteiros de calçadas sobre as árvores ali plantadas, bem como, sobre o atrativo destas paisagens ao bem estar dos pedestres.

A composição dos canteiros é variada numa cidade, com diferenças visíveis dos bairros em direção ao centro urbano e, em alguns casos, de uma vizinhança para outra, conforme características culturais, desenvolvimento local e poder econômico.

A percepção desses ambientes e gosto por determinados tipos paisagísticos depende de fatores como personalidade, orientação ambiental e grau de educação (TODOROVA et al., 2004).

De uma forma geral, pode-se dizer que tais canteiros poderiam ter três formas de composição: somente calçada, calçada mais grama e calçada mais grama com espécies arbustivas e herbáceas, podendo também, é claro, existir árvores nas três formas. Nestas três formas, a permeabilidade do solo varia conforme o material que o recobre e isto exerce influência sobre a dinâmica das águas pluviais e sobre o desenvolvimento das espécies arbóreas. Os gramados e outros vegetais de forração do solo, ao contrário das superfícies impermeáveis, contribuem para o manejo de água no solo, sua retenção, filtração e

\footnotetext{
${ }_{4}^{4}$ JACOBS, A. Keynote: looking, learning, making. Places v.11, n.2, p.3-7, 1997.
} 
purificação. Porém, para Daly (2008) as necessidades de irrigação dos gramados diferem das árvores, podendo a irrigação excessiva danificar o tronco das árvores e causar podridão das raízes.

A dispersão lateral das raízes das árvores é restringida pela alta densidade do solo, a qual praticamente impossibilita a penetração das raízes (KOPINGA, 1991). Este autor cita alguns exemplos de estudos sobre o volume de solo necessário para o bom crescimento de uma árvore, por metro quadrado de copa. Discute ele a importância de se estabelecer este fator para cada espécie sob diferentes condições de solo, já que a infiltração das águas pluviais e o consumo de água pelas árvores variam conforme os fatores de volume de solo e área da copa. Estes seriam fatores de condicionamento do manejo de áreas permeáveis nos centros urbanos, sobre os quais são efetivados os trabalhos de arborização, bem como, sobre as possibilidades de composição de canteiros com espécies herbáceas e trepadeiras de forma a causar menores conflitos e problemas com as espécies arbóreas.

LIRA FILHO (2002) afirma que o paisagista no Brasil goza da liberdade de construir jardins baseados numa realidade florística de muita riqueza, podendo criar associações de grande expressividade, desde que respeite as exigências da compatibilidade ecológica e estética. Este fato possibilita a composição diversificada e variada dos canteiros urbanos, pois os moradores de uma rua, se imbuídos do intuito e da orientação adequada, podem elaborar um tratamento paisagístico local.

TODOROVA et al. (2004) afirmaram que as árvores de rua, em combinação com outras plantas menores, são vistas como mais estéticas do que uma simples estrutura feita apenas com árvores. Porém, BIONDI e ALTHAUS (2005) citaram que o uso de cobertura vegetal na área do canteiro é polêmico, pois podem ocorrer prejuízos às árvores conforme a espécie de forração utilizada, pela ocorrência de competição por nutrientes e água. Esta competição vai depender muito das dimensões do canteiro, das exigências das espécies utilizadas e das condições gerais do solo.

Segundo MESSENGER (1976), uma planta pode interferir sobre a outra de duas formas: alelopática ou competição. Esta competição pode ser por água, nutrientes (principalmente nitrogênio), luz, calor, dióxido de carbono, oxigênio ou espaço para desenvolvimento, podendo afetar todas as partes da árvore, porém, os efeitos adversos sobre as raízes são dificilmente perceptíveis. Para esse mesmo autor, as características dos horizontes de superfície são de grande importância quando o espaço disponível ao crescimento das árvores é pequeno, dependendo disto o potencial de crescimento.

Este trabalho teve por objetivo fazer um levantamento exploratório sobre a composição florística de calçadas em Curitiba-PR, especificando as características das calçadas (áreas permeáveis), das árvores e da vegetação encontrada nos canteiros da 
arborização de ruas. Com base na vegetação encontrada foram também sugeridas outras espécies de forração para diversificar a composição existente.

\section{MATERIAL E MÉTODOS}

Esta pesquisa foi realizada na cidade de Curitiba, no Estado do Paraná, a qual está localizada entre as coordenadas $25^{\circ} 25^{\prime} 48^{\prime \prime}$ e $49^{\circ} 16^{\prime} 15^{\prime \prime} \mathrm{W}$. O clima característico desta região é do tipo Cfb na classificação de Köppen (subtropical úmido mesotérmico, com verões quentes e invernos com geadas freqüentes, sem estação seca). As temperaturas médias anuais nos meses quentes e frios são inferiores a $22^{\circ} \mathrm{C}$ e $18^{\circ} \mathrm{C}$ respectivamente, e a temperatura média anual é igual a $17^{\circ} \mathrm{C}$. A média anual da umidade relativa do ar fica em torno de $85 \%$ e da precipitação entre 1.300 e $1.500 \mathrm{~mm}$ anuais, sem deficiência hídrica ao longo do ano (MAACK, 1981).

Os dados analisados neste trabalho foram coletados em quatro segmentos de rua da cidade de Curitiba. Cada um destes segmentos correspondeu a um trecho de rua que liga duas quadras, estando limitado por outras duas ruas transversais. Estes segmentos foram escolhidos ao acaso, levando-se em conta apenas a informação de que, em determinadas vizinhanças da cidade, a população local utiliza a área pública (canteiro) para desenvolver projetos de paisagismo junto com a arborização viária local.

Cada segmento foi considerado como uma amostra, medindo-se nesta, do lado direito e esquerdo da via, a área da calçada, do passeio, dos acessos, da rua, e, por desconto da área total da amostra, a área do canteiro ou área permeável.

Dentro das áreas permeáveis, foram quantificadas todas as espécies arbóreas, arbustivas, herbáceas, palmeiras, trepadeiras e as gramíneas utilizadas na forração do solo e na composição paisagística.

Para cada espécie encontrada, foram obtidas, em literatura, informações sobre o tipo de caule, bem como, sobre a cor da floração que desenvolvem e a altura de crescimento atingida. Salienta-se que as informações sobre o tipo de sistema radicular das espécies observadas nas amostras foram disponibilizadas devido ao conhecimento prático da forma vegetativa das espécies, por conhecimento prévio do tipo de associação caule-raiz ou por pesquisa em referência bibliográfica, quando disponível.

Estas informações serviram para elaborar uma análise e reflexão preliminar da compatibilidade entre plantas junto ao nível do solo e da adequabilidade destas na forração do solo. 


\section{RESULTADOS E DISCUSSÃO}

Na Tabela 01, são apresentados os locais das amostras e as espécies arbóreas encontradas nas parcelas. Estes dados mostram um resultado tecnicamente não recomendável na arborização urbana, pois, além daquelas espécies arbóreas padrões da arborização de rua (aquelas plantadas pela prefeitura municipal), foram encontradas outras de porte e características diferentes plantadas nos canteiros, numa mesma quadra. Isto pode ser um fator não desejável, pois causa dificuldades no trato silvicultural e no manejo da arborização; além da diluição do efeito estético da árvore, conforme BIONDI e ALTHAUS (2005). Mas, por outro lado, poderia ser um fator desejável, se tecnicamente ordenado, pois, em plantios heterogêneos as chances de problemas causados por pragas ou doenças são, proporcionalmente, menores. Há, no entanto, que se tomar o devido cuidado em permitir à população o plantio de espécies arbóreas, sem auxílio técnico habilitado. Além disso, esta atividade da população, em fazer plantios voluntários, indica uma grande preocupação em melhorar o ambiente em que vivem. Para a cidade de Curitiba, isto é um bom indicativo de conscientização ambiental.

Tabela 01 - Localização das parcelas e espécies arbóreas encontradas.

\begin{tabular}{|c|c|c|}
\hline Parcela & Localização & Espécies Arbóreas \\
\hline 01 & $\begin{array}{l}\text { Rua Clóvis Bevilaquia, entre Ruas Recife } \\
\text { e Reinaldo Egon Heldinger - Bairro } \\
\text { Cabral }\end{array}$ & $\begin{array}{l}\text { Angico, Monjoleiro*, Dedaleiro*, Cerejeira } \\
\text { do Japão }\end{array}$ \\
\hline 02 & $\begin{array}{l}\text { Entre Clóvis Bevilaquia, entre Ruas } \\
\text { Reinaldo Egon Heldinger e Alfredo } \\
\text { Wenske - Bairro Cabral }\end{array}$ & $\begin{array}{l}\text { Angico*, Cinamomo, Dedaleiro*, } \\
\text { Jacarandá, Ficus, Pitangueira, Alfeneiro, } \\
\text { Acer, Caroba, Ipê Roxo, Quaresmeira }\end{array}$ \\
\hline 03 & $\begin{array}{l}\text { Rua Dr. Faivre, entre Ruas Nilo Cairo e } \\
\text { Comendador Macedo - Bairro Centro }\end{array}$ & $\begin{array}{l}\text { Koeleutéria, Dedaleiro, Cinamomo, } \\
\text { Sibipiruna, Ipê amarelo }\end{array}$ \\
\hline 04 & $\begin{array}{l}\text { Rua Júlia da Costa, entre Ruas Prudente } \\
\text { de Moraes e Brigadeiro Franco - Bairro } \\
\text { Mercês }\end{array}$ & Cinamomo* \\
\hline
\end{tabular}

NOTA:*Espécies padrão da rua, plantadas pela Prefeitura Municipal de Curitiba-PR.

A Tabela 02 apresenta informações sobre o total de áreas permeáveis e impermeáveis nas calçadas das parcelas amostradas. Percebe-se que houve diferença expressiva do percentual de área permeável, variando de 17,85\% a 35,53\%. Essa diferença resulta do fato de que as duas parcelas com menores taxas de permeabilidade estão situadas em bairros adjacentes à região central da cidade (onde ocorre maior impermeabilização do solo) e as outras duas estão localizadas em bairro mais afastado, com característica mais residencial, de médio a alto padrão de vida, em menor densidade de ocupação. Este fato é destacado por HARDT e MILANO (1994), os quais afirmaram que 
quanto mais elevadas são a ocupação do solo e a densidade demográfica, menores são as quantidades de áreas permeáveis.

Tabela 02 - Áreas totais de cada componente das parcelas amostradas.

\begin{tabular}{ccccccc}
\hline Parcela & $\begin{array}{c}\text { Total } \\
\text { Parcela } \\
\left(\mathbf{m}^{2}\right)\end{array}$ & $\begin{array}{c}\text { Total } \\
\text { Rua } \\
\left(\mathbf{m}^{2}\right)\end{array}$ & $\begin{array}{c}\text { Calçada } \\
\left(\mathbf{m}^{\mathbf{2}}\right)\end{array}$ & $\begin{array}{c}\text { Impermeável } \\
(\text { passeio+acessos) } \\
\left(\mathbf{m}^{2}\right)\end{array}$ & $\begin{array}{c}\text { Permeável } \\
(\mathbf{c a n t e i r o )} \\
\left(\mathbf{m}^{\mathbf{2}}\right)\end{array}$ & $\begin{array}{c}\text { Permeabilidade } \\
(\mathbf{\%})\end{array}$ \\
\hline 01 & $2.400,00$ & 840,00 & $1.560,00$ & 781,38 & 778,62 & 32,44 \\
02 & $2.400,00$ & 840,00 & $1.560,00$ & 707,36 & 852,64 & 35,53 \\
03 & $2.088,00$ & 840,00 & $1.248,00$ & $1.014,96$ & 233,04 & 18,67 \\
04 & $1.700,00$ & 654,50 & $1.045,50$ & 742,10 & 303,40 & 17,85 \\
\hline
\end{tabular}

Nas cidades, a permeabilidade do solo e drenagem de águas pluviais é fato de grande importância. Segundo ARAÚJO et al. (2000), áreas impermeáveis como telhados, ruas, estacionamentos, passeios e outros alteram as características de volume e qualidade do ciclo hidrológico. Para WOODWORTH (2007), a urbanização causa um decréscimo na qualidade da água e um acréscimo em seu uso. Esta mesma autora citou que as paisagens locais são fatores críticos ao manejo e à retenção da água em ambientes urbanos.

Nessas paisagens locais inserem-se as calçadas onde são feitos os plantios da arborização urbana. As diferenças encontradas na dimensão das áreas permeáveis, conforme o distanciamento da área central, causam diferenças na capacidade de evitar o escoamento superficial de águas pluviais e de permitir a infiltração da água no solo. Percebe-se que a gestão da arborização urbana influencia a manutenção de áreas permeáveis e, por conseguinte, o gerenciamento das águas pluviais, permitindo mais ou menos a permeabilidade dos solos e o escoamento das águas.

A Tabela 03 apresenta a relação das espécies encontradas na amostragem, e a Tabela 04 apresenta algumas especificações botânicas das espécies observadas: forma de vida, tipo de caule, tipo de sistema radicular, cor da floração, altura e origem.

Tabela 03 - Espécies herbáceas, arbustivas e arbóreas utilizadas nas composições paisagísticas das amostras avaliadas.

\begin{tabular}{lll}
\hline Nome vulgar & Nome científico & Família \\
\hline Grama-são-carlos & Axonopus compressus (Sw.) P. Beauv. & Poaceae \\
Grama-esmeralda & Zoysia japonica Steud & Poaceae \\
Grama-japonesa & Zoysia tenuifolia Willd. e Thiele & Poaceae \\
Grama-preta & Ophiopogon japonicus (L. f.) Ker Gawl. & Liliaceae \\
Falsa-íris & Neomarica caerulea (Ker Gawl.) Sprague & Iridaceae \\
Mini-lantana-lilás & Lantana sellowiana Link e Otto & Verbenaceae \\
Jasmim & Gardenia jasminoides J. Ellis & Rubiaceae \\
Areca-bambu & Dypsis lutescens (H. Wendl.) Beentje e J. Dransf. & Arecaceae \\
Lantana & Lantana camara L. & Verbenaceae \\
Pingo-de-ouro & Duranta repens L. "Aurea" & Verbenaceae \\
Schefflera & Schefflera arboricola (Hayata) Merr. & Araliaceae \\
Moréia & Dietes bicolor Sweet ex G. Don & Iridaceae \\
Margarida & Chrysanthemum frutescens L. & Asteraceae \\
Costela-de-adão & Monstera deliciosa Liebm. & Araceae \\
\hline
\end{tabular}




\begin{tabular}{lll}
\hline Continuação Tabela 03... & & \\
\hline Nome vulgar & Nome científico & Família \\
\hline Ardísia & Ardisia crenata Sims & Myrsinaceae \\
Espada-de-são-jorge & Sansevieria trifasciata var. laurentii (de Wild.) N.E. Br & Liliaceae \\
Roseira & Rosa x grandiflora Hort & Rosaceae \\
Aloe-candelabro & Aloe arborescens Mill & Asphodelaceae \\
Poinsétia & Euphorbia pulcherrima Willd. & Euphorbiaceae \\
Azaléia & Rhododendron simsii Planch & Ericaceae \\
Piriquito & Alternanthera ficoidea (L.) R. Br. & Amaranthaceae \\
Buxo & Buxus sempervirens L. & Buxaceae \\
Mini-vinca & Catharantus roseus (L.) G. Don & Apocynaceae \\
Begônia & Begonia cucullata Willd. & Begoniaceae \\
Tuya & Thuja orientalis "Compacta" & Cupressaceae \\
Clorofito & Chlorophytum comosum (Thunb.) Jacques & Liliaceae \\
Coroa-de-cristo & Euphorbia milii Des. Moul. & Euphorbiaceae \\
Yuca & Yuca elephantipes Regel ex Trel. & Liliaceae \\
Agapanto & Agapanthus africanus (L.) Hoffm. & Liliaceae \\
Hera & Hedera canariensis Willd. & Araliaceae \\
Tuia-jacaré & Juniperus horizontalis Moensch & Cupressaceae \\
Bambu-mossó & Phyllostachys pubescens Mazel & Poaceae \\
Bromélia-imperial & Alcantarea imperialis (Carrière) Harms & Bromeliaceae \\
Cica & Cycas revoluta Thunb. & Cicadaceae \\
Jupipero & Juniperus chinensis "L. Plumosa" & Cupressaceae \\
Fênix & Phoenix roebelenii O' Brien & Arecaceae \\
Bromélia & Neoregelia sp & Bromeliaceae \\
Palmeira-leque & Livistona chinensis & Arecaceae \\
Abacaxi-roxo & Tradescantia spathacea Sw. & Commelinaceae \\
Bambuza & Bambusa gracilis hort. Ex Rivière e C. Rivière & Poaceae \\
Estrelícia & Strelitzia reginae Aiton & Musaceae \\
Gávea & Agave attenuata Salm-Dyck & Amaryllidaceae \\
Kaizuka & Juniperus chinensis "Torulosa" & Cupressaceae \\
Rabo-de-gato & Acalypha reptans Sw. & Euphorbiaceae \\
Hemerocalis & Hemerocallis flava L. & Liliaceae \\
Murta & Myrtus communis & Myrtaceae \\
\hline & &
\end{tabular}

Constata-se, na Tabela 03, que, embora seja apenas uma amostragem exploratória, existe uma diversidade de espécies nos canteiros de calçadas da cidade de Curitiba, fato que não é tão comum em outras cidades brasileiras. Esta diversidade de espécies se deve ao interesse dos proprietários das residências e comércios, pois a legislação municipal existente em Curitiba (Lei Municipal 11.596/2005 e Decreto Municipal 1066/2006) delega ao proprietário de imóvel a responsabilidade pela execução e manutenção das calçadas e passeios, facultando a este, por conseqüência, a execução de ajardinamento nos canteiros, exceto a implantação do componente arbóreo, de atribuição exclusiva da Prefeitura Municipal. Na Figura 01 são mostradas fotografias que exemplificam diferentes composições paisagísticas nos canteiros avaliados, a execução desse tipo de trabalho por moradores e a associação de árvores de rua com diferentes tipos de grama. 


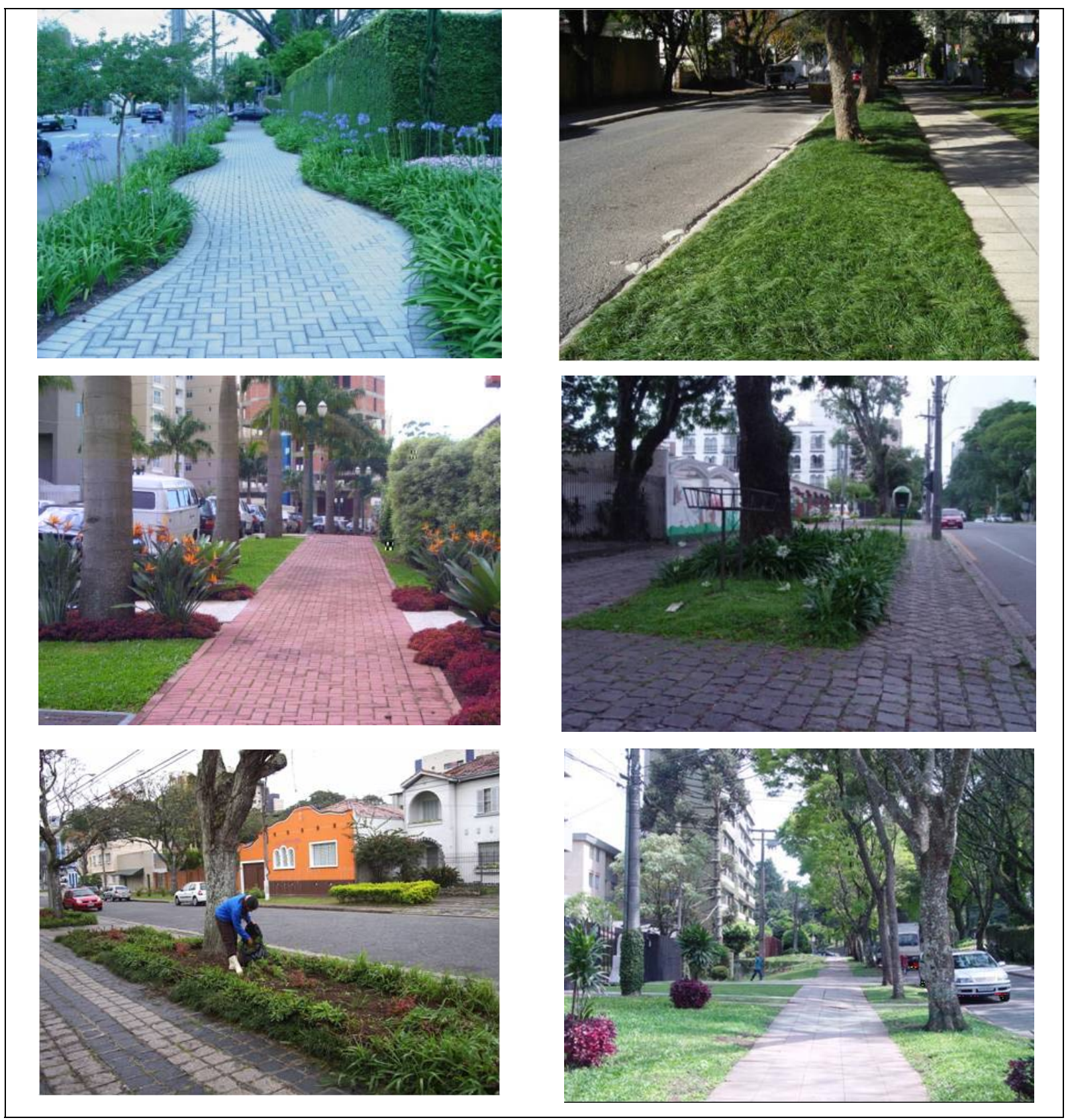

Figura 01 - Exemplos de calçadas avaliadas na cidade de Curitiba-PR, suas composições paisagísticas nos canteiros e execução de trabalhos de composição por morador local.

A diversidade de vegetação que se utiliza nas calçadas não se restringe apenas ao uso de árvores como componentes da arborização de ruas, conforme se observa na Tabela 04. Em diversos locais da cidade, além dos pontos amostrados, pode-se visualmente perceber que a composição dos canteiros é feita exclusivamente com árvores associadas a alguns tipos de gramas e outras plantas, sendo não corriqueiras as composições paisagísticas encontradas neste estudo. Estas composições paisagísticas acabam sendo um atributo de alguns bairros, em decorrência da disponibilidade de calçadas amplas e permeáveis, que possibilitam a realização da livre expressão paisagística. 
Composição de canteiros na arborização...

Tabela 04 - Características botânicas das espécies amostradas.

\begin{tabular}{|c|c|c|c|c|c|c|}
\hline Planta & $\begin{array}{c}\text { Forma } \\
\text { vegetativa }\end{array}$ & Caule & Raiz & Flores & $\begin{array}{l}\text { Altura } \\
\text { (cm) }\end{array}$ & $\begin{array}{c}\text { Nativa do } \\
\text { Brasil }\end{array}$ \\
\hline Grama-são-carlos & Herb & $\mathrm{Rz}$ & Ad & --- & --- & Sim \\
\hline Grama-esmeralda & Herb & $\mathrm{Rz}$ & Ad & --- & $15-20$ & Não \\
\hline Grama-japonesa & Herb & $\mathrm{Rz}$ & Ad & --- & $50-80$ & Não \\
\hline Grama-preta & Herb & Es/Acaule & $\mathrm{Fa}$ & --- & $400-600$ & Não \\
\hline Falsa-íris & Herb & $\mathrm{Rz}$ & Ad & $A z$ & $30-60$ & Sim \\
\hline Mini-lantana-lilás & Herb & $\mathrm{Ht}$ & $\mathrm{Rm}$ & $\mathrm{Rs} / \mathrm{Rx} / \mathrm{Br}$ & --- & Não \\
\hline Jasmim & Arb & $\operatorname{Tr}$ & $\mathrm{Pi}$ & $\mathrm{Br}$ & $60-120$ & Não \\
\hline Areca-bambu & Arb & Co/Rz & Ad & Am & 300 & Não \\
\hline Lantana & Herb & $\mathrm{Ht}$ & $\mathrm{Pi}$ & $\mathrm{Am} / \mathrm{La} / \mathrm{Rs} / \mathrm{Br}$ & $100-150$ & Sim \\
\hline Pingo-de-ouro & Arb & $\operatorname{Tr}$ & $\mathrm{Pi}$ & $A z / R x$ & $300-600$ & Não \\
\hline Schefflera & Arb & $\operatorname{Tr} / \mathrm{Rz}$ & Ad & $\mathrm{Br} / \mathrm{Cr}$ & $1500-2000$ & Não \\
\hline Moréia & Herb & $\mathrm{Rz}$ & Ad & Am & $200-300$ & Não \\
\hline Margarida & Herb & $\mathrm{Ht}$ & $\mathrm{Rm}$ & $\mathrm{Am} / \mathrm{Br} / \mathrm{Rs}$ & $80-120$ & Não \\
\hline Costela-de-adão & Arb & $\mathrm{Rz}$ & Ad & --- & 2000 & Não \\
\hline Ardísia & Herb & $\mathrm{Ht}$ & $\mathrm{Rm}$ & Rs & $20-30$ & Não \\
\hline Espada-de-são-jorge & Herb & $\mathrm{Rz}$ & Ad & $\mathrm{Br}$ & 60 & Não \\
\hline Roseira & Arb & $\mathrm{Ht}$ & $\mathrm{Pi}$ & $\mathrm{Rs} / \mathrm{Ve} / \mathrm{Am} / \mathrm{Br}$ & $120-150$ & Não \\
\hline Aloe-candelabro & Herb & $\operatorname{Tr}$ & $\mathrm{Rm}$ & Ve & $100-150$ & Não \\
\hline Poinsétia & Arb & $\operatorname{Tr}$ & $\mathrm{Pi}$ & Ve/Br/Rs/Am & $300-500$ & Não \\
\hline Azaléia & Arb & $\operatorname{Tr}$ & $\mathrm{Pi}$ & Rs & $15-20$ & Não \\
\hline Piriquito & Herb & $\mathrm{Ht}$ & $\mathrm{Rm}$ & $\mathrm{Vd} / \mathrm{Br}$ & $40-60$ & Sim \\
\hline Buxo & Arb & $\mathrm{Ht}$ & $\mathrm{Pi}$ & --- & $200-500$ & Não \\
\hline Mini vinca & Arb & $\mathrm{Ht}$ & $\mathrm{Pi}$ & Ve/Rx/Rs/Br & 100 & Não \\
\hline Begônia & Herb & $\mathrm{Ht}$ & $\mathrm{Rm}$ & $\mathrm{Br} / \mathrm{Rs} / \mathrm{Ve}$ & $15-20$ & Sim \\
\hline Tuya & Arv & $\operatorname{Tr}$ & $\mathrm{Pi}$ & --- & $600-1100$ & Não \\
\hline Clorofito & Herb & Acaule & $\mathrm{Pi}$ & $\mathrm{Br}$ & $15-20$ & Não \\
\hline Coroa-de-cristo & Arb & $\mathrm{Ht}$ & $\mathrm{Pi}$ & Ve/Rs/Am/Br & $50-80$ & Não \\
\hline Yuca & Arb & $\mathrm{Tr} / \mathrm{Ht}$ & $\mathrm{Rm}$ & $\mathrm{Br}$ & $400-600$ & Não \\
\hline Agapanto & Herb & $\mathrm{Rz}$ & $\mathrm{Ad}$ & $A z$ & $30-60$ & Não \\
\hline Hera & Herb & Tr/Es & $\mathrm{Ad}$ & --- & --- & Não \\
\hline Tuia-jacaré & Arb & $\mathrm{Tr} / \mathrm{Ra}$ & $\mathrm{Pi}$ & --- & $60-120$ & Não \\
\hline Bambu-mossó & Arb & Co/Rz & $\mathrm{Ad}$ & --- & $1000-2000$ & Não \\
\hline Bromélia-imperial & Herb & Acaule & $\mathrm{Rm}$ & Am & $100-150$ & Sim \\
\hline Cica & Arb & $\operatorname{Tr}$ & $\mathrm{Rm}$ & --- & $300-400$ & Não \\
\hline Junípero & Arv & $\mathrm{Tr} / \mathrm{Ra}$ & $\mathrm{Pi}$ & --- & $1500-2000$ & Não \\
\hline Fênix & Arv & Co & $\mathrm{Ad}$ & $\mathrm{Cr}$ & $200-300$ & Não \\
\hline Bromélia & Herb & Acaule & $\mathrm{Rm}$ & --- & --- & --- \\
\hline Palmeira-leque & Herb & Ep & $\mathrm{Ad}$ & --- & 1500 & Não \\
\hline Abacaxi roxo & Herb & Acaule & $\mathrm{Rm}$ & $\mathrm{Br}$ & $20-30$ & Não \\
\hline Bambusa & Arb & Co/Rz & $\mathrm{Ad}$ & --- & 300 & Não \\
\hline Estrelícia & Herb & $\mathrm{Rz}$ & $\mathrm{Ad}$ & $\mathrm{La}$ & $120-150$ & Não \\
\hline Gávea & Arb & $\mathrm{Tr} / \mathrm{Ht}$ & $\mathrm{Rm}$ & --- & $100-150$ & Não \\
\hline Kaizuka & Arv & $\operatorname{Tr}$ & $\mathrm{Pi}$ & --- & 500 & Não \\
\hline Rabo-de-gato & Herb & $\mathrm{Ht}$ & $\mathrm{Ad}$ & Ve & $15-20$ & Não \\
\hline Hemerocalis & Herb & $\mathrm{Rz}$ & $\mathrm{Ad}$ & $\mathrm{Am} / \mathrm{La}$ & $40-60$ & Não \\
\hline Murta & Arb & $\operatorname{Tr}$ & $\mathrm{Pi}$ & $\mathrm{Br} / \mathrm{Rs}$ & $300-500$ & Não \\
\hline
\end{tabular}


Do total de espécies amostradas (Tabela 04), constatou-se que 24 espécies (52,17\%) apresentam forma de vida herbácea, 18 espécies (39,13\%) apresentam forma de vida arbustiva e 04 espécies (8,69\%), a forma de vida arbórea. Também, do total amostrado, constatou-se que 18 espécies (39,13\%) apresentam raiz adventícia, 15 espécies $(32,60 \%)$ apresentam raiz pivotante, 12 espécies $(26,09 \%)$ apresentam raiz ramificada e 01 espécie $(2,17 \%)$ apresenta raiz fasciculada. As famílias botânicas mais expressivas, em número de espécies, foram: Liliaceae com 06 espécies (13,04\%), Poaceae com 05 espécies (10,87\%) e Cupressaceae com 04 espécies (8,69\%).

Destes dados, depreende-se que, mesmo empiricamente, a população tem procurado utilizar espécies de forma vegetativa herbácea na composição paisagística, e isto reflete o interesse em compor canteiros com texturas, cores e estruturas diversificadas logo nos primeiros centímetros acima do nível do solo, a fim de embelezar o ambiente e aproximar a população a esses locais. Deve-se, no entanto, atentar para o fato de que ocorre a utilização de espécies com características arbóreas num percentual significativo, fato este não recomendado, em virtude da maior dificuldade de manejo das árvores (diferentes arquiteturas de copa, diferentes tamanhos) e diluição do efeito estético proporcionado pelas árvores padrão da arborização da rua. O que preocupa um pouco é a utilização expressiva de espécies da família Poaceae, a qual forma um tapete na superfície do solo, com vantagem para o ambiente e desvantagem para a planta consorciada, devido à maior competição (principalmente pela disponibilidade de água), pois o sistema radicular e caule dessas espécies são mais superficiais e densos.

Do total de espécies amostradas, somente 13,04\% (06 espécies) são consideradas nativas do Brasil, segundo LORENZI e SOUZA (1995). Das 40 espécies exóticas deste estudo, 35\% delas são consideradas invasoras em algum país, conforme trabalho realizado por BIONDI e PEDROSA-MACEDO (2008), mas somente uma delas é oficialmente declarada invasora no Brasil: a grama preta (Ophiopogon japonicus).

Somente 16 espécies (34,78\%), das 46 encontradas, apresentam caule em rizoma ou estolão. Apesar do baixo número de espécies, ocorre a utilização freqüente de uma mesma espécie e, em muitos canteiros, como única forma de associação com a vegetação arbórea.

Os dados levantados sobre as espécies arbustivas e herbáceas utilizadas pela população (Tabela 03) faz com que se reflita sobre o uso exclusivo da grama como objeto de composição para forração dos canteiros na arborização urbana. Esse tipo de forração, por possuir caule em rizoma ou estolão, acaba formando uma densa camada sobre o solo, dificultando a infiltração de água que poderia ser disponibilizada mais prontamente às raízes das árvores plantadas nas ruas. Pode ocorrer, por isso, maior competição por água e nutrientes, os quais apresentam limitações de disponibilidade no solo urbano (por fatores 
Composição de canteiros na arborização...

como $\mathrm{pH}$, teor de umidade e temperatura), além do espaço restrito disponível ao crescimento e desenvolvimento, em muitos trechos de calçada. Então, se faz necessário o planejamento correto do uso, do tipo e da densidade de espécies herbáceas junto às espécies arbóreas componentes da arborização urbana, de forma a diminuir os danos por competição.

Vale salientar que o uso do gramado é essencial e preferível em determinadas áreas onde o trânsito de pedestres é intenso, tais como parques municipais ou praças e área de comércio, pois este tipo de vegetal suporta mais fortemente o pisoteio. Em alguns desses locais, o plantio consorciado das árvores com a grama pode oferecer nenhuma ou quase nenhuma competição porque as árvores estão em áreas extensas e sem obstáculos físicos. Já as árvores nas calçadas, além dos obstáculos físicos subterrâneos (canalização, alicerce, meio-fio, aterros, rocha, etc.) que não podem ser vistos na superfície, passam a dividir com a grama a umidade e nutrientes disponíveis, em áreas extremamente pequenas. É claro que entre um canteiro cimentado e um com grama é preferível o canteiro com grama. Mas, entre um canteiro com grama e um com plantas de forração (espécies que cobrem mais o solo pela parte aérea do que pelas raízes/caules), é preferível a segunda opção.

Considerando-se a compatibilidade e o impacto junto às árvores, a grama é preferível ao asfalto ou concreto, pois para CELESTIAN (2004), houve diferença significativa entre a temperatura de quatro diferentes superfícies de recobrimento do solo. No estudo conduzido, a temperatura sob, no nível e acima da camada asfáltica, foi maior que as encontradas para superfícies de concreto e gramado. Nesse mesmo estudo, concluiu-se que a temperatura da rizosfera sob o asfalto de estacionamentos é alta o suficiente para causar injurias às raízes ou para limitar o volume efetivo de solo disponível ao crescimento das árvores. Em Curitiba, observa-se, em alguns bairros, que o calçamento original foi substituído por uma camada asfáltica para formação do passeio, o qual se estende até a base do componente arbóreo da arborização das ruas.

Já HOLMAN ${ }^{5}$, citado por CELESTIAN (2004), afirmou que superfícies impermeáveis, como asfalto e concreto, absorvem, retêm e reirradiam mais calor por unidade de área que superfícies vegetadas como gramados, os quais são capazes de dissipar esta forma de energia por meio da evapotranspiração.

Ressalta-se, então, a importância da manutenção de áreas permeáveis no entorno das árvores da arborização de ruas, numa extensão tão maior quanto possível (dependendo das características de tráfego local de pedestres), para efetivamente proporcionar o crescimento destas e evitar gastos com substituições de árvores desvitalizadas por causa do local inapropriado ao crescimento e dos danos gerados em conseqüência disso.

\footnotetext{
${ }^{5}$ HOLMAN, J. P. 1986. Heat Transfer. McGraw-Hill, New York, NY. 676p.
} 
As raízes dos gramados são agressivas e crescem mais rapidamente que as raízes das árvores, sendo este fato decisivo ao desenvolvimento das plantas arbóreas, principalmente para aquelas recentemente plantadas (DALY, 2008). Este princípio deveria ser observado com mais atenção e aplicado, principalmente, em locais onde se está estabelecendo o plantio de árvores para composição da arborização de ruas ou de parques, pois, nesses locais, geralmente, a grama já está plantada. Atentando-se para esta observação, poder-se-ia diminuir os danos causados às mudas plantadas, bem como, as perdas ocasionadas.

Além disso, a manutenção do gramado (corte), na maioria das vezes, proporciona danos ao tronco. DALY (2008) afirmou que as árvores podem ser danificadas pelos equipamentos utilizados na manutenção de gramados (tanto o tronco quanto as raízes, por compactação do solo). Então, o uso do gramado deveria ser evitado até um determinado limite no entorno das árvores, a fim de diminuir os danos potenciais, principalmente em locais onde a manutenção dos canteiros é feita por pessoas despreparadas.

No ambiente urbano, as plantas ornamentais podem estar sujeitas a vários fatores inadequados de solo, clima, práticas culturais, tráfego de pessoas e de veículos, e inúmeros outros riscos. Além disso, as mudanças que ocorrem nas propriedades físicas do solo afetam a umidade e a aeração, as quais restringem o sistema radicular da planta com a redução de sua atividade (BIONDI, 1995). Estes fatores estão relacionados e afetam a qualidade e quantidade de solo permeável nas cidades, limitando o uso de plantas mais exigentes quanto a solo e comprometendo os trabalhos de manejo. Torna-se necessário, então, buscar formas de melhorar as características físicas do solo antes do plantio de árvores ou plantas herbáceas nos canteiros.

A prática de utilização dos canteiros de calçadas para composição paisagística, se tecnicamente conduzida, pode ampliar a melhoria das condições da arborização de ruas e seus diversos efeitos e benefícios à população. Neste contexto, COELHO et al. (1999), num estudo sobre a vegetação urbana do Sul do Estado de Minas Gerais, afirmaram que o plantio de forrações no entorno das árvores não é muito comum, mas que ele melhora, em muito, a estética da arborização, recobre o solo e possibilita melhores adubações e irrigações.

Espécies encontradas neste estudo, como o clorofito, o rabo de gato, a moréia, o agapanto, a hera, entre outras, poderiam ser alternativas de forração utilizadas com mais freqüência, desde que atendendo a um parâmetro de densidade máxima de plantas. Talvez a disseminação desta possibilidade de uso viesse a ter um forte papel de Educação Ambiental integrando o morador à sua rua, à arborização urbana, de forma a criar um vínculo maior entre estes, beneficiando a manutenção das árvores, com menores danos e conseqüente diminuição de custos do órgão público com ações de reparo e substituição. 
Composição de canteiros na arborização...

Em outros locais da cidade de Curitiba, fora das parcelas amostradas, foi observado o uso de alguns tipos de forração do solo, em substituição ao gramado de uso comum, conforme mostra a Tabela 05. Constata-se que há interesses por parte da população na busca por alternativas ao uso da grama, como forma de melhorar a qualidade visual e estética dos canteiros, quebrando a monotonia da textura e coloração proporcionada pelas gramas.

Tabela 05 - Forrações diferentes em uso nos canteiros, fora das áreas amostradas.

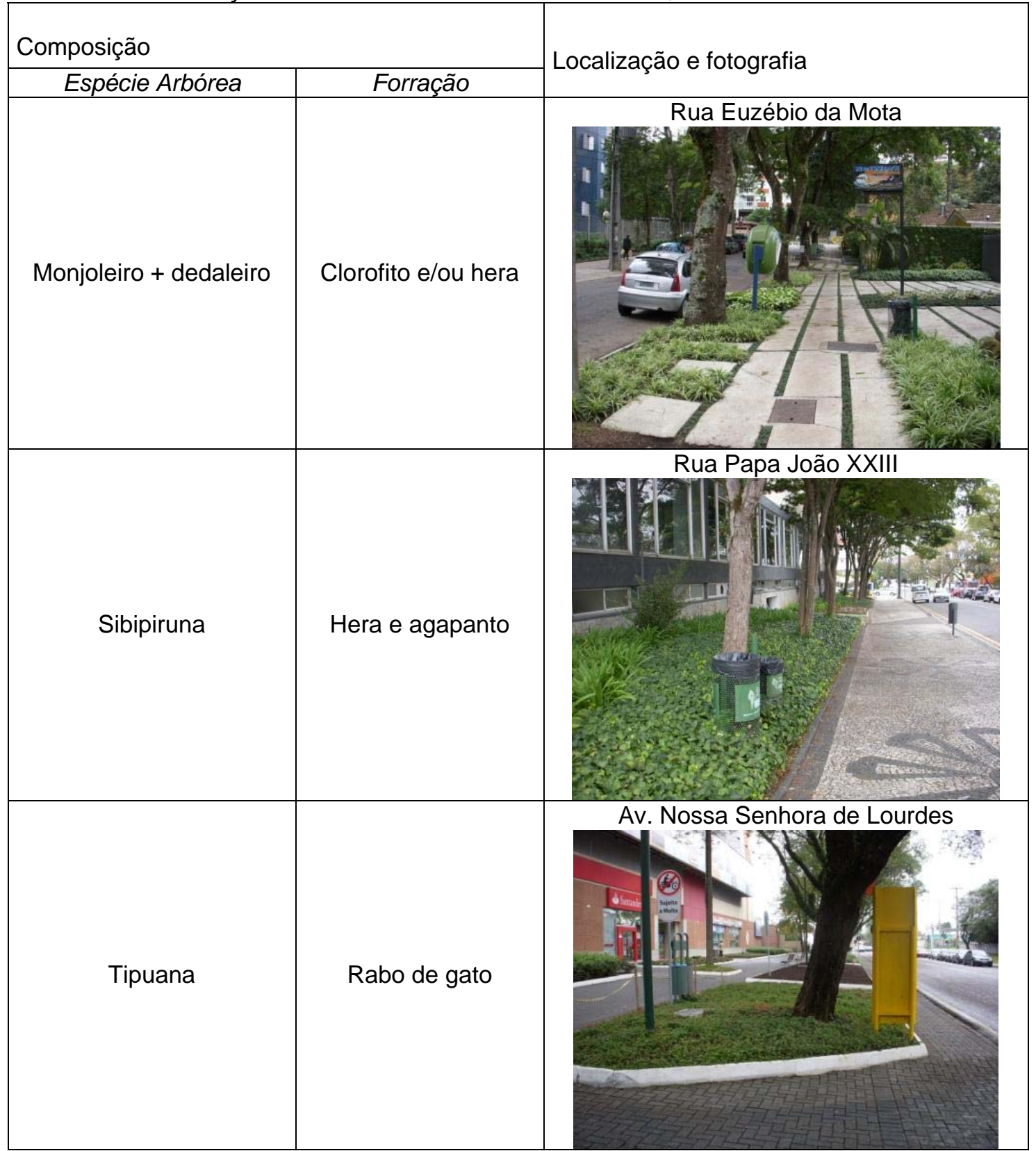

A composição de canteiros deve ser um projeto criterioso, cuidando-se para não gerar impactos negativos às árvores plantadas, principalmente devido à compactação excessiva do solo no entorno das árvores, adição de plantas alelopáticas ou produtos 
químicos para controle de pragas, pois, conforme afirmou GILMAN (2006), barreiras físicas ou químicas podem influenciar o crescimento das raízes, em profundidade ou lateralmente. Em conseqüência disso, podem ocorrer as perdas de mudas e desvitalização de árvores adultas.

Algumas sugestões de espécies herbáceas para o plantio em canteiros de calçadas são apresentadas na Tabela 06, em substituição ao uso consorciado com diferentes tipos de gramas, visando a melhores benefícios, com menor competição entre raízes e caules. Estas forrações acabam por quebrar a visibilidade monótona de uma rua e adicionam textura e cor à paisagem. Vale salientar que se deve priorizar as espécies nativas, se possível, em virtude da adaptação ao local e das condições ecológicas das espécies.

Tabela 06 - Sugestões de espécies herbáceas para forração de canteiros.

\begin{tabular}{ll}
\hline \multicolumn{1}{c}{ Nome vulgar } & \\
\hline Érica & Cuphea gracilis Kunth \\
Onze-horas & Portulaca grandiflora Hook \\
Trevo & Oxalis latifolia Kunth \\
Hemerófico \\
Gota-de-orvalho & Hemerocallis flava L. \\
Maranta & Ctelvulus pussillus Choisy \\
Calatea & Calathea makenheimiana (E. Morr) K. Schum \\
Samambaia & Nephrolepsis sp. \\
Periquito & Alternanthera ficoidea (L.) R. Br. \\
Curculigo & Curculigo capitulata \\
Cóleo & Coleus blumei Benth. \\
Clorofito & Chlorophytum comosum (Thunb.) Jacques \\
Ajuga & Ajuga reptans L. \\
Piléia & Pilea cadierei Boiss. and Spruner \\
Gazânia & Gazania rigens (L.) Gaertn. \\
Russélia & Russelia equisetiformis Schlecht. e Cham \\
Setecrésia & Tradescantia pallida (Rose) D.R. Hunt var. purpurea Boom \\
\hline
\end{tabular}

O tipo de planta mais adequada ao plantio nos canteiros, próximas às árvores, depende do tipo de caule e de raiz que estas apresentam e da densidade de plantas por unidade de área, já que o entrelaçamento do sistema radicular ou caulinar (se forem rizomas ou se forem rasteiros) pode ser tão inconveniente quanto o uso de grama, para uma mesma unidade de área (devido à maior densidade superficial). Isto pode dificultar a permeabilidade superficial do solo e a infiltração mais imediata de águas pluviais para as camadas mais inferiores, além de favorecer a competição por nutrientes disponíveis.

Para não haver competição excessiva no solo, devem-se priorizar espécies que oferecerem uma boa cobertura foliar e menor densidade de raízes. A cobertura foliar da superfície do solo proporciona um consórcio mais harmonioso entre as necessidades fisiológicas das espécies. Além disso, esse tipo de forração impede o pisoteio dos pedestres nos canteiros, evitando a compactação da superfície do solo. 
Composição de canteiros na arborização...

Outro fator a ser considerado na composição de canteiros é que todas as formas de vegetação contribuem para o melhoramento do visual - as árvores quebram a continuidade das fachadas dos prédios e promovem um delineamento do espaço; arbustos ancoram estruturas no chão e gramas e forração definem as bordas dos pavimentos (SMARDON ${ }^{6}$, citado por TODOROVA et al., 2004).

\section{CONCLUSÕES E RECOMENDAÇÕES}

Com os resultados obtidos constatou-se que as calçadas analisadas possuem um bom percentual de áreas permeáveis que permitem a execução de trabalhos de composição paisagística nos canteiros. Algumas espécies encontradas e utilizadas como forração não são adequadas para compor os canteiros, devido principalmente ao tamanho dessas (aquelas de porte arbóreo, fora do padrão da arborização da rua, e de porte arbustivo); outras espécies, devido ao denso crescimento na camada superficial do solo, deveriam ser utilizadas apenas onde existem grandes áreas disponíveis ao bom desenvolvimento das árvores da arborização urbana.

Algumas das espécies sugeridas para forração dos canteiros, em substituição à grama, já são utilizadas pela população em locais visitados, além das parcelas amostradas, para efetuar diferentes composições paisagísticas com melhores condições de textura e cores.

Constatou-se também a necessidade de trabalhos de melhoramento da aeração do solo via descompactação das camadas superficiais antes de qualquer plantio, preferencialmente na extensão do canteiro (já que as raízes se estenderão pelo entorno), para melhorar a captação e infiltração de águas pluviais e desenvolvimento das plantas.

Recomenda-se realizar estudos mais detalhados, seguindo um delineamento estatístico de amostragem rigorosa, para obtenção de dados que representem melhor a compatibilidade entre raízes/caules de árvores, gramas e outras plantas, na camada superficial do solo e primeiros 0,50m de altura.

Torna-se relevante também elaborar estudos sobre o volume de solo necessário para o bom crescimento de uma árvore nos canteiros urbanos, a fim de justificar melhores critérios para a manutenção de áreas permeáveis e a extensão dessas, bem como, a área de influência crítica entre o componente arbóreo e a forração.

\footnotetext{
6 SMARDON, R. Perception and aesthetic of urban environment: review of the role of vegetation. Landscape and Urban Planning, Amsterdam, v.15, n.1-2, p. 85-106, 1988.
} 


\section{REFERÊNCIAS BIBLIOGRÁFICAS}

ARAÚJO, P.; TUCCI, C.E.M.; GOLDENFUM, J. A avaliação da eficiência dos pavimentos permeáveis na redução de escoamento superficial. Revista Brasileira de Recursos Hídricos, Porto Alegre, v. 5, n. 3, p 21-28, 2000.

BIONDI, D. Caracterização do estado nutricional de Acer negundo L. e Tabebuia chrysotricha (Mart. Ex DC.) Standl utilizadas na arborização urbana de Curitiba-PR. 146p. Tese (Doutorado em Ciências Florestais) - Setor de Ciências Agrárias, Universidade Federal do Paraná, Curitiba, 1995.

BIONDI, D.; ALTHAUS, M. Árvores de Rua de Curitiba - Cultivo e Manejo. Curitiba: FUPEF, 2005.

BIONDI, D.; PEDROSA-MACEDO, J. H. Plantas invasoras encontradas na área urbana de Curitiba (PR). Revista Floresta, Curitiba, v. 38, n.1, p. 129-144, 2008.

CELESTIAN, S. B.; MARTIN, C. A. Rhizosphere, surface, and air temperature patterns at parking lots in Phoenix, Arizona, U.S. Journal of Arboriculture, Champaign, IL, v. 3, n. 4, p. 245-252, 2004.

COELHO, S. J.; PÁDUA, T.; BARROS, L. M. Aspectos da vegetação urbana e algumas características culturais do Sul do Estado de Minas Gerais. Lavras: UFLA/CEMIG, 48p. 1999.

DALY, T. Trees and turf coexist uneasily but can successfully grow together if managed properly. GTA Today, Georgia, v. 23, n. 4, Jul/Ago 2008.

GILMAN, E. F. Deflecting roots near sidewalks. Journal of Arboriculture, Champaign, IL, v. 32, n. 1. p, 18-23, 2006.

HARDT, L. P. A.; MILANO, M. S. Avaliação de áreas permeáveis e impermeáveis como subsídio ao planejamento de sistemas de áreas verdes urbanas: aplicação a Curitiba-PR. In: Congresso Brasileiro de Arborização Urbana, 2., 1994, São Luiz. Anais..., São Luiz: SBAU, 1994. p. 353-376.

KOPINGA, J. The effects of restricted volumes of soil on the growth and development of street trees. Journal of Arboriculture, Champaign, IL, v. 17, n. 3, p. 57-93. 1991.

LIRA FILHO, J. A. Paisagismo: elementos de composição estética. Viçosa: Aprenda Fácil, 2002. 173p..

LORENZI, H.; SOUZA, H. M. Plantas Ornamentais no Brasil: arbustivas, herbáceas e trepadeiras. $3^{\mathrm{a}}$ ed. Nova Odessa: Plantarum, 1995.

MAACK, R. Geografia física do Estado do Paraná. $2^{\mathrm{a}}$ Ed. Rio de Janeiro: J. Olympio, 1981.

MESSENGER, A. S. Root competition: grass effects on trees. Journal of Arboriculture, Champaign, IL, v. 2, n. 12, p. 228-230, 1976.

TODOROVA, A.; ASAKAWA, S; AIKOH, T. Preferences for and attitudes towards street flowers and trees in Sapporo, Japan. Landscape and Urban Planning, Amsterdam, v. 69, n. 4, p.403-16. 2004. 
Composição de canteiros na arborização...

WOODWORTH, M. K. Healthy landscape vital to water system. GTA Today, Georgia, v. 22, n. 6, Nov/Dez 2007. 